Research Report

\title{
Compressive Strength Test on Calcium Hydroxide with Propolis Combination
}

\author{
Ira Widjiastuti ${ }^{1}$, Setyabudi ${ }^{1}$, M.Mudjiono ${ }^{1}$, Erika Setyowati $^{2}$ \\ ${ }^{1}$ Staff Department of Conservative Dentistry, Dental Medicine Faculty, Airlangga University, Surabaya- \\ Indonesia \\ ${ }^{2}$ Undergraduate Student of Dental Medicine Faculty, Airlangga University, Surabaya-Indonesia
}

\begin{abstract}
Background: Calcium hydroxide is a dental material used as a gold standard for pulp capping materials. However, calcium hydroxide has several weaknesses which cause many researchers to look for alternative ingredients that come from nature. Propolis in the field of dentistry has long been used because of its ability as an anti-inflammatory, anti-microbial, anti-fungal, and can cure scars. The combination of calcium hydroxide and propolis is proven to have good biocompatibility and anti-bacterial properties. One of the requirements of pulp capping material is to have sufficient compressive strength. Therefore, a research to test the compressive strength value of the combination of calcium hydroxide with propolis is needed. Purpose: To find out the difference in compressive strength of the combination of calcium hydroxide-propolis with a ratio of 1: 1, 1: 1.5, and 1: 2. Methods: The study used 4 treatment groups with each group consisting of 6 replications. Group 1 is a combination of calcium hydroxide-propolis with a ratio of 1: 1, group 2 with a ratio of 1: 1.5, group 3 with a ratio of 1: 2, and a positive control group using calcium hydroxide - sterile aquadest. Calcium hydroxide powder and propolis extract liquid is mixed according to comparison and printed on a cylindrical mold with the size of $4 \mathrm{~mm} \times 6 \mathrm{~mm}$. Then, the compressive strength was tested using an Autograph test instrument. Result: Compressive strength was smaller in group 3 compared to group 2, group 2 compared to group 1, and group 1 compared to the control group. Conclusion: In calcium hydroxide-propolis combination, the more propolis extract used in the combination the lower the compressive strength of the combination will be.
\end{abstract}

Key words: Combination of Calcium Hydroxide-Propolis; Compressive strength.

Correspondence: Ira Widjiastuti, Dental Meidicine Faculty, Airlangga University, Surabaya-Indonesia, (+62)87854573451,ira-w@fkg.unair.ac.id

\section{INTRODUCTION}

Calcium hydroxide is a gold standard pulp capping material because it has a great antibacterial properties, ability to induce mineralization, and also has low cytotoxicity. ${ }^{1}$ However, calcium hydroxide also has weaknesses. This material is highly soluble, has a weak adhesive quality, causes resorption in primary teeth, creates a "tunnel defect" in tertiary dentine which forms under calcium hydroxide, and is less effective in eliminating certain bacteria. All these weaknesses leads to several researches to try combining calcium hydroxide with natural products to gain pulp capping material with better ability. One of that natural product is propolis.

Propolis is a natural resin substance obtained by honey bees through various plants to build and repair honeycomb. Propolis has anti-bacterial, antiinflammatory properties, non-toxic, causes pulp regeneration, does not cause inflammation, and shows dentinal tubular formation without porous. 5,6 Adding propolis extract on calcium hydroxide can increase the antimicrobial activity of 
calcium hydroxide, biocompatible, and does not cause inflammation. ${ }^{4,7}$

Pulp capping material has to meet several conditions, one of which has sufficient compressive strength. ${ }^{8}$ Sufficient compressive strength enable pulp capping material to remain in position despite receiving force from operative procedure and resisting condensation compressive force from the material above. Compressive strength is needed so that the pulp capping material is able to withstand pressure during placement and during the lifetime of the material above it. The pulp capping material should withstand indirect pressure forces from mastication. ${ }^{8,11}$

Some studies have combined calcium hydroxide and propolis. Comparisons used in the combination of calcium hydroxide-propolis are also various. There are studies that use a combination ratio of calcium hydroxidepropolis $1: 1,1: 1.5$, and $1: 2 .^{7,12}$

It is not yet known how the material compressive strength of the three comparisons in these studies. Because of that, the aim of this study is to determine the difference in compressive strength of the combination of calcium hydroxidepropolis with a ratio of $1: 1,1: 1.5$, and 1 : 2. This study is expected to provide information on the compressive strength of the combination of calcium hydroxidepropolis with a ratio of $1: 1,1: 1.5$, and 1: 2 and to be considered an alternative material for pulp capping.

\section{MATERIAL AND METHOD}

The study was conducted using 4 treatment groups with each group consisting of 6 replications. Group 1 is a combination of calcium hydroxidepropolis with a ratio of $1: 1$, group 2 is 1 : 1.5, group 3 is $1: 2$, and group 4 is a positive control group using calcium hydroxide - sterile distilled water.

Propolis extract was obtained by maceration technique from Apis melifera honeycomb using $96 \%$ ethanol, then diluted to produce a propolis solution with a concentration of $8 \% .{ }^{13}$ Calcium hydroxide used in this research is a pro analysis Merck brand calcium hydroxide powder.

Samples are made using 4 × $6 \mathrm{~mm}$ diameter molds according to ISO 9917-1: 2007 standard. Calcium hydroxide powder with propolis extract / sterile distilled water is stirred on a glass slab using a cement spatula until it is homogeneous and then put into the mold. The lower part of the mold is given a celluloid strip and placed on a glass slab and the combination of calcium hydroxide-propolis is put into the mold with a plastic filling instrument, the mixture is added from the mold and then given a celluloid strip on top and pressed with another glass slab on top as shown in figure $1 .^{14}$

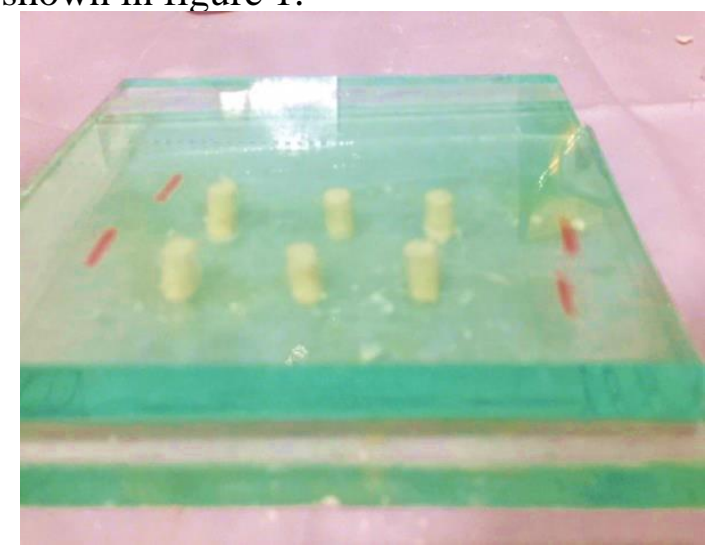

Figure 1. Making of calcium hydroxidepropolis sample

After the sample hardens, it is removed from the mold and then physically evaluated. Uneven or distorted samples are not used as samples. Then, the sample is left for 48 hours at $37 \mathrm{oC}^{14}$

Testing the compressive strength value of the sample used the Autograph tool. The sample is placed in the center of the pressure device by positioning the vertical axis of the sample perpendicular to the flat plane. The autograph tool is turned on and the pressing part moves slowly with a pressure of $1 \mathrm{kN}$ and the speed of $1 \mathrm{~mm} /$ minute presses to shred. After the sample is destroyed, the numbers printed on the autograph device are recorded. The 
numbers listed in $\mathrm{kgF}$ are converted in Newton and then divided into crosssectional areas so that the compressive strength is obtained in Pascal units according to the following formula.

$$
\mathrm{C}=4 \mathrm{P} / \pi \mathrm{D}^{2}
$$

Information :

$\mathrm{C}=$ Compressive power value (in Mega Pascal)

$\mathrm{P}=$ The maximum force applied to the sample when the sample is destroyed (in Newton)

$\mathrm{D}=$ Diameter of sample (in millimeters)

The data obtained were processed using Kolmogorof-Smirnof statistical analysis for normality test, Levene test for Homogeneity test, One Way Anova for difference test, and Post hoc test to see comparison between samples (Tukey HSD).

\section{RESULTS}

From figure 2 it can be seen that the average compressive strength of positive controls is $1.24 \mathrm{MPa}$, group I 0.84 $\mathrm{MPa}$, group II $0.54 \mathrm{MPa}$, and group III $0.24 \mathrm{MPa}$.

The results of data analysis show that data is normally distributed and homogeneous. In the ANOVA test results obtained $\mathrm{p}=0.000(\mathrm{p}<0.05)$, which means there are differences between treatment groups. The Tukey HSD test results showed that each sample group had a significant difference between one sample group and another. This means a combination of calcium hydroxidepropolis with a ratio of $1: 1.1: 1.5$ and $1: 2$ have significant compressive strength differences.

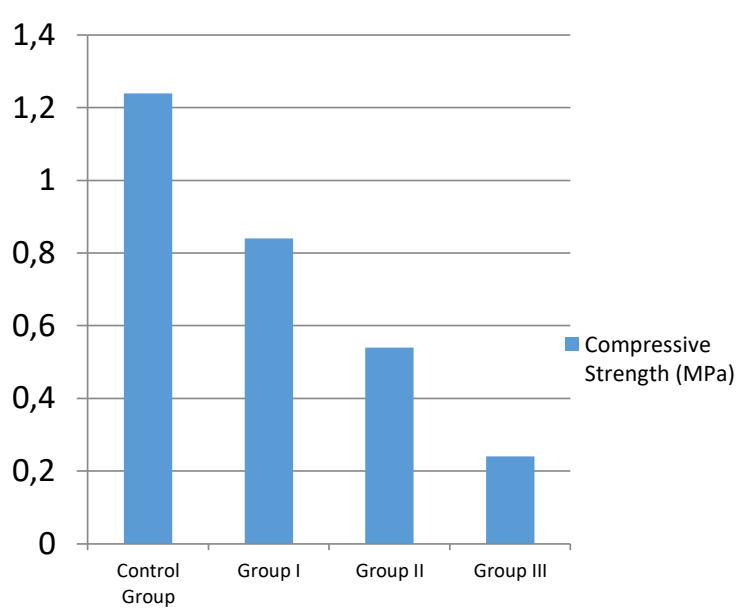

Figure 2. Diagram of research result

From the results of data analysis it was found that the combination of calcium hydroxide-propolis with a ratio of 1: 2 had a lower compressive strength than the combination of calcium hydroxidepropolis with a ratio of $1: 1.5$ and a combination of calcium hydroxidepropolis with a ratio of $1: 1.5$ compressive is lower than the combination of calcium hydroxide-propolis with a ratio of 1: 1 . The combination of calcium hydroxidepropolis with a ratio of 1 : 1 has a compressive strength lower than the control group.

\section{DISCUSSION}

In the results of the study it can be seen that the combination of calcium hydroxide-propolis with a ratio of $1: 1,1$ : 1.5, and 1: 2 has a significant difference in compressive strength. The increase in the ratio of propolis to calcium hydroxide causes compressive strength to decrease significantly according to the results of the study. This is because with the increase in propolis extract in the combination of calcium hydroxide-propolis, the structure of the combination in the form of solid after the setting is affected and results in 
decreased compressive strength. There are several things that can affect the compressive strength of a combination of calcium hydroxide with propolis.

In the combination of calcium hydroxide with propolis, there is a bond between molecules that occurs between hydrogen atoms aromatic compounds from propolis with oxygen atoms from water or ethanol. This bond is a weak hydrogen bond. $^{15}$ Based on phytochemical tests carried out along with the increasing number of propolis from a ratio of $1: 1$ to 1: 1.5 and $1: 2$, the concentration of aromatic compounds will increase. Therefore, the weaker bonds will be more so that the material structure will have lower compressive strength. In addition to hydrogen bonds, aromatic compounds in propolis have van der waals bonds with hydroxyl groups derived from calcium hydroxide and active ingredients in propolis. The van der waals bond is a weak bond and can make molecules in the material bond tightly so that it produces a weaker structure and will make the compressive strength lower. ${ }^{15}$

Propolis contains phenolic acid, this compound is a weak acid and is able to react with strong bases to form salt. In the combination of calcium hydroxide with propolis, phenolic acid can react with calcium hydroxide which is a strong base forming salt and water. ${ }^{16}$ Compressive strength can also be reduced by the acidbase reaction that occurs This acid-base reaction can form salt and water. Material with a higher water level will certainly produce material with a more watery consistency, this can affect the structure of the material and ultimately reduce the compressive strength. ${ }^{17}$ Physically, mixing with the addition of liquid propolis extract will decrease the ratio of powder: liquid and make saturated liquid which is not entirely able to react with calcium hydroxide powder to produce a less strong structure. This can ultimately make the compressive strength of the material drop. $^{18}$
The $\mathrm{pH}$ of the mixture can affect the compressive strength of a material. At higher $\mathrm{pH}$ the material has higher surface strength and lower porosity. At lower $\mathrm{pH}$, changes in material microstructure occur due to increased porosity and eventually will result in decreased compressive strength. This is because in an acidic atmosphere, $\mathrm{OH}$ - ions which can play a role in the initial stage hardening are disrupted. ${ }^{19-21}$ Several studies have shown that the addition of propolis to calcium hydroxide can reduce the $\mathrm{pH}$ value of calcium hydroxide. $^{4,22,23}$ Therefore, there are the possibility that propolis $\mathrm{pH}$ can affect the compressive strength of a combination of calcium hydroxide with propolis. However, in several studies of the effect of $\mathrm{pH}$ on the compressive strength of material, $\mathrm{pH}$ can be found to have no significant effect due to the interaction of the particle content and size of complex substances in the material. ${ }^{24}$

From the research result, showed that increases of propolis extract in the combination will result in decreasing compressive strength. This research hasn't prove yet if $\mathrm{pH}$ really played role in the compressive strength of calcium hydroxide-propolis combination.

\section{REFERENCES}

1. Baranwal R, Singh BD, Dubey A AA. Calcium hydroxide in dentistry: A Review . Calcium Hydroxide in Dentistry. Chettinad Heal City Med J. 2016;5(1):3-7.

2. Hilton TJ. Keys to Clinical Success with Pulp Capping: A Review of the Literature. Oper Dent. 2010;34(5):615-625.

3. Jahromi M, Ranjbarian P, Shiravi S. Cytotoxicity Evaluation of Iranian Propolis and Calcium Hydroxide on Dental Pulp Fibroblasts. JODDD. 2014;8(3):130-133. doi:10.5681/joddd.2014.024.

4. Cavalcanti YW, Machado M, Moraes T De, Padilha WW. Antimicrobial activity and $\mathrm{pH}$ evaluation of Calcium Hydroxide associated with natural products. Braz Dent Sci. 2010;13(8):49-54.

5. Hwu Y, Lin F. Effectiveness of Propolis 
on Oral Health : A Meta-Analysis. J Nurs Res. $\quad 2014 ; 22(4): 221-230$. doi:10.1097/jnr.0000000000054.

6. Ahangari Z, Naseri M, Jalili M, Yasaman M, Mashhadiabbas F, Torkaman A. Effect of Propolis on Dentin Regeneration and the Potential Role of Dental Pulp Stem Cell in Guinea Pigs. Cell J. 2012;13(4):223228 .

7. Mori GG, Rodrigues S, Tieko S. Biocompatibility of a Calcium HydroxidePropolis Experimental Paste in Rat Subcutaneous Tissue. 2014;25:104-108.

8. Qureshi A, Soujanya E. Recent Advances in Pulp Capping Materials: An Overview. 2014;8(1):316-321. doi:10.7860/JCDR/2014/7719.3980.

9. Negm A, Hassanien E, Abu-seida A, Nagy M. Physical evaluation of a new pulp capping material developed from portland cement. 2016;8(3). doi:10.4317/jced.52748.

10. Alsubait S. Effects of different acid etching times on the compressive strength of three calcium silicate-based endodontic materials. J Int Oral Heal. 2016;8(3):328331. doi:10.2047/jioh-08-03-06.

11. Kayahan MB, Sunay H, Kaptan RF, Meraji N. Effect of Acid Etching Procedures on the Compressive Strength of 4 Calcium Silicate - based Endodontic Cements. $J$ Endod. 2013;39(12):1646-1648. doi:10.1016/j.joen.2013.09.008.

12. Ozorio J, Carvalho L, Neto M, Perez D. Standardized propolis extract and calcium hydroxide as pulpotomy agents in primary pig teeth. J Dent Child. 2012;79(2):53-58.

13. Ramanauskiene $\mathrm{K}$, Inkeniene AM. Propolis oil extract: Quality analysis and evaluation of its antimicrobial activity. Nat Prod Res. 2011;25(15):1463-1468. doi:10.1080/14786419.2010.529440.

14. Natale LC, Rodrigues MC, Xavier TA, Simões A, de Souza DN, Braga RR. Ion release and mechanical properties of calcium silicate and calcium hydroxide materials used for pulp capping. Int Endod J. 2014;48(1):89-94. doi:10.1111/iej.12281.
15. Zheng Y, Zhou Y, Liang Q, Chen D, Guo R. A theoretical study on the hydrogenbonding interactions between flavonoids and ethanol / water. 2016. doi:10.1007/s00894-016-2968-2.

16. Scouten R, Schlosberg, Charles G, Richard H. The Organic Chemistry of Calcium: A New Phenol Separation/Recovery Approach. Sciene Res. 2011;4(8):180-187.

17. Francisconi L, Freitas A, Scaffa P, Mondelli R. Water Sorption And Solubility Of Different Calciumm Hydroxide Cements. J Appl Oral Sci. 2009;17(5):427-431.

18. Anusavice KJ, Shen C, Rawls HR. 2013. Philip's Science of Dental Material. 12th ed. St. Louis:Elsevier. p:189.

19. Namazikhah MS, Nekoofar MH, Sheykhrezae MS, Salariyeh S, Hayes SJ. The effect of $\mathrm{pH}$ on surface hardness and microstructure of mineral trioxide aggregate. Interna. 2008;41:108-116. doi:10.1111/j.1365-2591.2007.01325.x.

20. Saghiri M, Garcia-godoy F, Asatourian A, Lotfi M, Banava S. Effect of $\mathrm{pH}$ on compressive strength of some modification of mineral trioxide aggregate. 2013;18(3). doi:10.4317/medoral.18922.

21. Basturk FB, Nekoofar MH. Effect of Varying Water-to-Powder Ratios and Ultrasonic Placement on the Compressive Strength of Mineral Trioxide Aggregate. $J$ Endod. 2015;41(4):531-534. doi:10.1016/j.joen.2014.10.022.

22. Montero JC, Mori GG. Assessment of ion diffusion from a calcium hydroxidepropolis paste through dentin. 2012;26(4):318-322.

23. Pujirahayu N, Ritonga $\mathrm{H}$, Uslinawaty Z. Properties And Flavonoids Content In Propolis Of Some Extraction Method Of Raw Propolis. IJPPS. 2014;6(6).

24. Kaplan T. Influence of Different Vehicles on the $\mathrm{pH}$ and Surface Tension of Calcium Hydroxide Pastes. 2013;(6):57-60. 
Conservative Dentistry Journal Vol.9 No.1 Januari-Juni 2019 :28-32 